\title{
Mini-Review
}

\section{Hepatic Lipase, High Density Lipoproteins, and Hypertriglyceridemia}

\author{
Cynthia Chatterjee and Daniel L. Sparks \\ From the Atherosclerosis, Genetics and Cell Biology Group, \\ University of Ottawa Heart Institute, Ottawa, Ontario, Canada
}

\begin{abstract}
Hepatic lipase (HL) is a lipolytic enzyme that contributes to the regulation of plasma triglyceride (TG) levels. Elevated TG levels may increase the risk of developing coronary heart disease, and studies suggest that mutations in the HL gene may be associated with elevated TG levels and increased risk of coronary heart disease. Hepatic lipase facilitates the clearance of TG from the very low density lipoprotein (VLDL) pool, and this function is governed by the composition and quality of high density lipoprotein (HDL) particles. In humans, $\mathrm{HL}$ is a liver resident enzyme regulated by factors that release it from the liver and activate it in the bloodstream. HDL regulates the release of HL from the liver and HDL structure controls HL transport and activation in the circulation. Alterations in HDL-apolipoprotein composition can perturb HL function by inhibiting the release and activation of the enzyme. HDL structure may therefore affect plasma TG levels and coronary heart disease risk. (Am J Pathol 2011, 178:1429-1433; DOI: 10.1016/j.ajpath.2010.12.050)
\end{abstract}

\section{Triglycerides and Heart Disease}

Elevated plasma triglyceride (TG) levels have been viewed as a risk factor for coronary heart disease (CHD) for more than a decade. ${ }^{1,2}$ Plasma TG levels are regulated by both synthesis and degradation of both very low density lipoprotein (VLDL) and chylomicron particles. The clearance of TG-rich lipoproteins from the circulation is controlled by the actions of lipoprotein lipase (LPL) and hepatic lipase $(\mathrm{HL})$ and by the interlipoprotein exchange of TG by cholesteryl ester transfer protein. Lipoprotein lipase is the predominant TG lipase and is responsible for hydrolyzing TG in chylomicrons and VLDL, whereas $\mathrm{HL}$ is both a phospholipase and a TG lipase and plays an important role in HDL metabolism and in the conversion of VLDL to LDL. ${ }^{3}$ Single nucleotide polymorphisms (SNPS) in the HL gene (LIPC) have been shown to asso- ciate with plasma lipid concentrations and increased $\mathrm{CHD}$ risk. ${ }^{4,5}$ Hepatic lipase deficiency is a result of relatively rare LIPC mutations that give rise to a loss in circulating $\mathrm{HL}$ activity (due to impaired secretion or inactive enzyme) and cause an increase in TG-rich HDL and VLDL remnants and increased CHD risk. ${ }^{1,6}$ The common SNPs have a variety of functional consequences. SNPs in the LIPC gene can be associated with both increased or decreased plasma levels of HDL cholesterol and with varied levels of $\mathrm{CHD}$ risk. ${ }^{7,8}$ Thus, unique SNPs may consequently confer both pro- and anti-atherogenic phenotypic consequences. This may explain why larger and more comprehensive studies have not observed an association between LIPC mutations and CHD risk. ${ }^{9}$ Variable phenotypes may be due in part to secondary factors, such as environment, lifestyle, and hormone levels, ${ }^{10}$ but depend primarily on the functional consequences of SNPS on $\mathrm{HL}$ activity. SNPs in the LIPC gene may directly affect the TGhydrolytic ability of $\mathrm{HL}$ and may indirectly affect $\mathrm{HL}$ by affecting the metabolism of $\mathrm{HDL}$ and its ability to control the function of $\mathrm{HL}$ in the circulation.

\section{Hepatic Lipase and the Liver}

Hepatic lipase is synthesized and secreted by the liver and binds to heparan sulfate proteoglycans (HSPG) on the cell surface of hepatocytes and endothelial cells. ${ }^{11,12}$ It has been known for more than 50 years that HSPGbound lipases can be released into the bloodstream by heparin. Hahn showed in 1943 that intravenous heparin stimulates TG hydrolytic activity in lipemic serum. ${ }^{13} \mathrm{Al}-$ though lipase activity is normally undetectable in human plasma, infusion of heparin increases both $\mathrm{HL}$ and $\mathrm{LPL}$ mass and activity in the bloodstream. ${ }^{14}$ Postheparin $\mathrm{HL}$ activity measurements have been used to reflect the functional levels of $\mathrm{HL}$ in an individual and are indirectly

Supported by the Heart and Stroke Foundation of Ontario and by a graduate scholarship from the Ontario Graduate Scholarship Program (OGS) (C.C.).

Accepted for publication December 3, 2010.

Address reprint requests to Daniel L. Sparks, Ph.D., University of Ottawa Heart Institute, 40 Ruskin St., Ottawa, ON K1Y 4W7, Canada. E-mail: dsparks@ottawaheart.ca. 


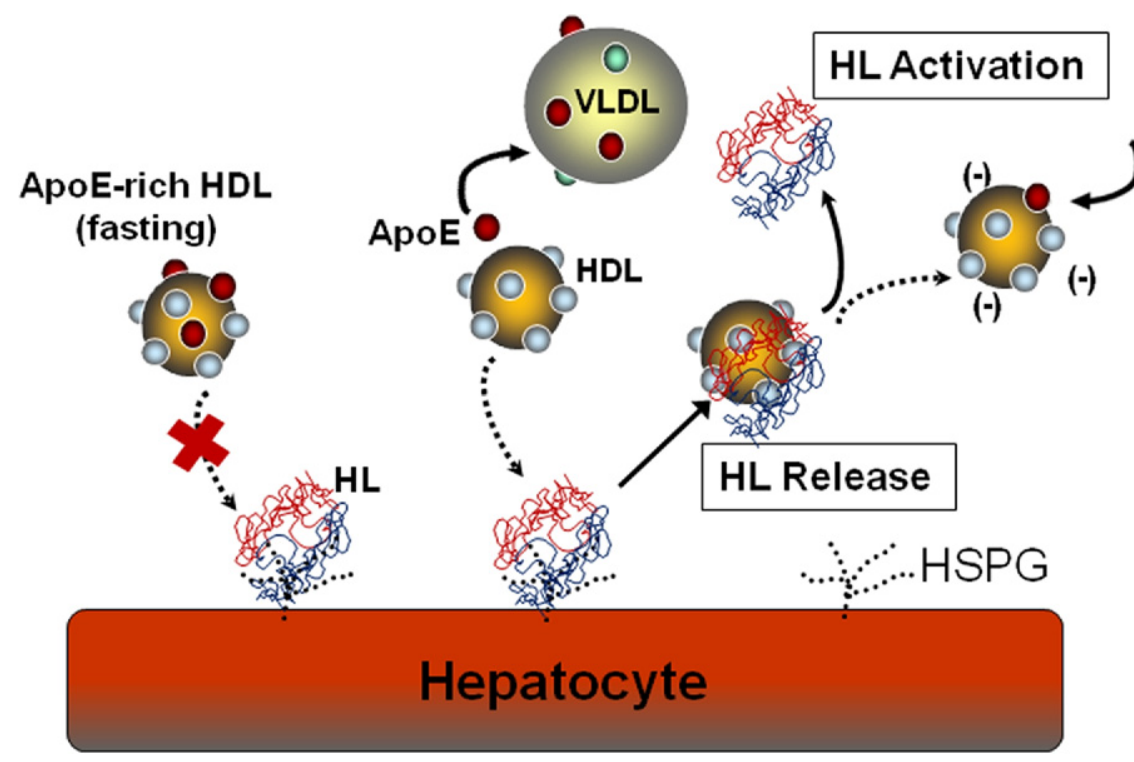

Figure 1. HDL regulates the release and activation of hepatic lipase (HL). The liver is a storage depot for catalytically inactive HL that is anchored to cell-surface heparan sulfate proteoglycans (HSPG). HDL binds to HL and releases the enzyme into the circulation. Fasting, ApoE-rich HDL is ineffective at releasing HL from cell surface HSPG During a postprandial response, HDL loses ApoE to VLDL and the ApoE-deficient HDL is more efficient at releasing HL from the cell surface. HDL compositional changes can then release HDLbound $\mathrm{HL}$ and activate the catalytic activity of the circulating enzyme. HDL therefore plays an important role in the mobilization and activation of HL.

measured by subtracting $\mathrm{NaCl}$-sensitive LPL activity from total postheparin lipase activity. Postheparin $\mathrm{HL}$ activity measurements are often elevated in hyperlipidemic patients and have been linked to an increased risk for developing $\mathrm{CHD} .{ }^{15,16}$ This has led to the suggestion that $\mathrm{HL}$ may be a pro-atherogenic enzyme. ${ }^{17,18}$ High postheparin $\mathrm{HL}$ activity may also be related to $\mathrm{CHD}$ risk as an indicator of reduced lipolytic function. Increased postheparin $\mathrm{HL}$ activity may represent an elevated storage pool of inactive $\mathrm{HL}$ in the liver, which results from defective release and activation of the enzyme. ${ }^{19-22}$ Cell surface HSPG-bound HL is a catalytically inactive enzyme, and HDL functions to mobilize and activate this liver-resident pool of HL. ${ }^{19}$

\section{Displacement of HSPG-Bound HL}

In humans, $\mathrm{HL}$ is found primarily in association with cellsurface HSPG on hepatocytes and endothelial cells of the liver, and it is therefore considered to be a liver resident enzyme. ${ }^{23}$ Specific residues in the $\mathrm{HL}$ protein regulate the association of $\mathrm{HL}$ with HSPG. ${ }^{24,25}$ Mapping studies using peptide arrays have identified two HL-heparin binding domains, one at the N-terminus (R310, K312, K314, R315) and another at the C-terminus (R473, K474, R476) ${ }^{25}$ In rodents, $\mathrm{HL}$ is also synthesized in the liver, but predominantly is found circulating in the bloodstream. ${ }^{26,27}$ Murine $\mathrm{HL}$ appears to be more readily displaced from cell-surface HSPG, because of differences in the C-terminal amino acid composition of the enzyme. ${ }^{27}$ Human $\mathrm{HL}$ can be released or liberated from cell-surface HSPG by both heparin and HDL. Some findings suggest that heparin interacts directly with the TG lipases and/or competes for binding sites on cell-surface HSPG. ${ }^{28}$ Findings from other studies indicate that heparin can act through protein kinase and calcium signaling pathways to stimulate $\mathrm{HL}$ release. ${ }^{29} \mathrm{HDL}$-dependent $\mathrm{HL}$ displacement is regulated by interactions between $\mathrm{HL}$ and HDL and is affected by both the lipid and the apolipoprotein composition of HDL. ${ }^{20-22}$

$\mathrm{HDL}$ composition directly affects the displacement of $\mathrm{HL}$ from cell-surface HSPG. ${ }^{20,21}$ Ramsamy et al ${ }^{20}$ showed that different subclasses of HDL have unique abilities to displace HL. The larger, more buoyant $\mathrm{HDL}_{2}$ fractions were more effective at displacing HSPG-bound HL than the smaller, dense $\mathrm{HDL}_{3}$ fractions. Rouhani et al ${ }^{21}$ showed that the various lipids in $\mathrm{HDL}$ have unique effects on $\mathrm{HL}$ displacement. Increases in HDL-TG and phospholipid content directly inhibited $\mathrm{HL}$ displacement from the cell surface, whereas changes in the other lipid components of $\mathrm{HDL}$ had little effect on $\mathrm{HL}$ release. More recently, HDL and serum isolated from postprandial subjects were shown to promote increased HL displacement, relative to samples from fasted subjects. ${ }^{22}$ The study showed that, even though postprandial HDL is TG-enriched, the lipoprotein is deficient in ApoE and is more effective than fasting $\mathrm{HDL}$ at binding to and displacing cell-surface HL. ${ }^{22}$

Hepatic lipase displacement appears to be controlled by HDL apolipoproteins and is stimulated by the ApoA-II content of HDL. ${ }^{21}$ ApoA-II increases the release of $\mathrm{HL}$ from HSPG by enhancing the association of $\mathrm{HL}$ with $\mathrm{HDL}$, and this increased association promotes an inhibition of $\mathrm{HL}$ activity. ${ }^{30,31}$ Conversely, $\mathrm{HL}$ displacement is inhibited by HDL-ApoE. ${ }^{22}$ Young et al ${ }^{22}$ showed that HDL isolated from female subjects was significantly better at displacing $\mathrm{HL}$ from cell surface HSPG, relative to HDL from male subjects. HDL isolated from the plasma of women also contained less ApoE, compared with that isolated from men. The study identified an inverse relationship between $\mathrm{HDL}-\mathrm{ApoE}$ content and the amount of circulating $\mathrm{HL}$ in the bloodstream. ${ }^{22}$ Increased ApoE content on HDL results in decreased $\mathrm{HL}$ release (Figure 1). Treatment of $\mathrm{HDL}$ with monoclonal ApoE antibodies, directed against epitopes in the glutamic acid-enriched N-terminus of ApoE, resulted in greater $\mathrm{HL}$ displacement, ${ }^{22}$ which sug- 
gests that the binding of $\mathrm{HL}$ to $\mathrm{HDL}$ may be sensitive to ApoE-dependent electrostatic properties of the lipoprotein. Other work has shown that HL activity is also dependent on electrostatic events that regulate the association of $\mathrm{HL}$ with HDL. ${ }^{31,32}$

Apolipoproteins are exchanged between $\mathrm{HDL}$ and the TG-rich lipoproteins, such as VLDL and intermediate density lipoprotein (IDL), during a postprandial lipemic event. ${ }^{33,34}$ Notably, ApoE and ApoCs are transferred from HDL to VLDL, where they act as lipolytic cofactors and receptor ligands. ${ }^{33} \mathrm{HDL}$ is therefore a storage depot for ApoE in the fasting state. A few hours after a meal, when plasma TG levels are high, ApoE moves from HDL to the TG-rich lipoproteins. ${ }^{33,35}$ This decrease in HDLApoE content appears to initiate the mobilization of $\mathrm{HL}$ from the hepatocyte cell surface to the vascular compartment (Figure 1), where the enzyme can then act to hydrolyze circulating TG. ${ }^{22}$ At the end of the lipemic response, ApoE returns to the HDL pool and blocks the ability of $\mathrm{HDL}$ to release $\mathrm{HL}$ from the liver.

\section{Regulation of HL Lipolytic Activity}

In humans, there appear to be two inactive pools of $\mathrm{HL}$, one that is HSPG-anchored in the liver and one that is HDL-bound and circulating in the bloodstream as an inactive enzyme. $\mathrm{HDL}$ therefore regulates $\mathrm{HL}$ activation in a two-step process, wherein HDL first binds and displaces $\mathrm{HL}$ from cell surface HSPG, and then the HDL dissociates and activates the circulating enzyme (Figure 1). Under fasting conditions, $\mathrm{HL}$ in the circulation appears to be catalytically inactive. Hepatic lipase activity can be detected in the plasma only after the enzyme is released from the liver by infusions of heparin. ${ }^{14}$ Although ApoA-I and HDL are also able to liberate $\mathrm{HL}$ from cell surface HSPG, the association of $\mathrm{HL}$ with $\mathrm{HDL}$ directly inhibits HL activity. ${ }^{19,31,32}$ Hepatic lipase is inactivated by its association with $\mathrm{HDL}$ particles containing both ApoA-I and ApoA-II. 30,31,36

Hepatic lipase activity is stimulated by the dissociation of $\mathrm{HL}$ from HDL (Figure 1) and controlled by lipoprotein electrostatic properties. ${ }^{31,32}$ Enrichment of HDL or serum with free fatty acid or anionic phospholipids (such as phosphatidylinositol, phosphatidic acid, or phosphatidylserine) increases the net negative charge on HDL and stimulates VLDL-TG hydrolysis by HL. ${ }^{32}$ An increase in $\mathrm{HDL}$ net negative charge was shown to reduce the binding of $\mathrm{HL}$ to $\mathrm{HDL}$ and to increase $\mathrm{HL}$ hydrolytic activity for all lipoprotein substrates. Hepatic lipase activity is therefore inhibited by the electrostatic-dependent association of $\mathrm{HL}$ with HDL. ${ }^{19,32}$ ApoA-II has been shown to increase the association of $\mathrm{HL}$ with $\mathrm{HDL}$ and to directly inhibit TG hydrolytic activity. ${ }^{30,31,36} \mathrm{ApoE}$ has the opposite effect. ApoE blocks the association of HL with HDL, ${ }^{22}$ but stimulates the HDL lipolytic activity of $\mathrm{HL} .{ }^{37}$ Women have been shown to have reduced plasma ApoE levels and increased circulating $\mathrm{HL}$, relative to men. ${ }^{22}$ Women also have a reduced postheparin $\mathrm{HL}$ activity, which has been thought to be a consequence of an inhibitory effect of estrogen on $\mathrm{HL}$ transcription. ${ }^{38}$ Reduced postheparin activity in women may therefore be in part a consequence of lower ApoE levels and reduced $\mathrm{HL}$ activation. ${ }^{22} \mathrm{ApoE}$ has been shown to directly interact with ApoA- $\|^{39}$ and, as such, may block ApoA-II-dependent association of HL with $\mathrm{HDL} .{ }^{31}$ ApoA-II may therefore control $\mathrm{HL}$ displacement and activation; its action is modulated by the amount of ApoE that can reside on the HDL particle surface.

In the circulation, HDL remains associated with $\mathrm{HL}$, to keep the enzyme in an inactive state, until hydrolytic activity is required. A tight regulation of $\mathrm{HL}$ lipolytic activity by $\mathrm{HDL}$ would be expected, given that $\mathrm{HL}$ is a phospholipase and potentially lytic to cell membranes. The liberation of $\mathrm{HL}$ by HDL from the cell surface therefore primes $\mathrm{HL}$ for its hydrolytic function by releasing the

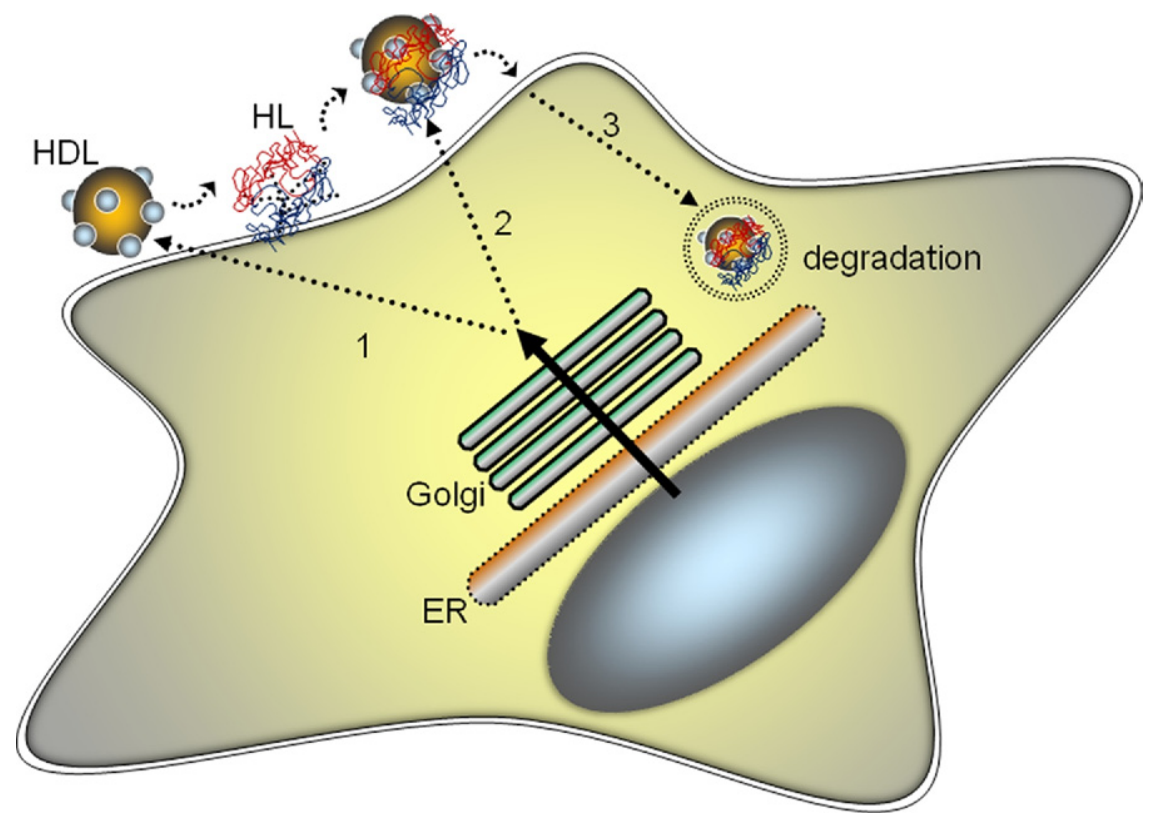

Figure 2. HDL and hepatic lipase (HL) secretion are coregulated. HDL secretion regulates HL release from the liver through three potential mechanisms: 1) newly secreted HDL binds and displaces cell surface HL, 2) HDL and HL associate intracellularly and are cosecreted, and/or 3) HDL and HL secretion are coregulated by plasma membrane reuptake and degradation pathways. ER, endoplasmic reticulum. 
anchored enzyme and enabling $\mathrm{HL}$ to gain access to circulating substrate. Increased lipase shuttling between substrate molecules has been shown to stimulate most interfacial lipolytic enzymes, including HL. ${ }^{40}$ Higher circulating levels of HDL-bound, inactive HL may be important to TG clearance. HDL isolated by sequential density ultracentrifugation from the plasma of female normolipidemic subjects was shown to contain significant $\mathrm{HL}$ mass. ${ }^{22}$ In contrast, HDL isolated from normolipidemic males and hyperlipidemic patients contains much less $\mathrm{HL}$ protein. An increased vascular pool of $\mathrm{HL}$ in women may therefore contribute to the reduced magnitude of postprandial lipemia that is often observed in women, relative to men. ${ }^{41}$ Increased HDL-bound $\mathrm{HL}$ in the circulation may also affect the remodeling of $\mathrm{HDL}$, because $\mathrm{HDL}_{2}$ formation has been shown to be increased in subjects who can clear alimentary TG more rapidly. ${ }^{42}$

\section{Regulation of HL Secretion from the Liver}

Because $\mathrm{HDL}$ can liberate $\mathrm{HL}$ from the cell-surface HSPG, it follows that hepatic HDL secretion would be expected to affect the release of $\mathrm{HL}$ from the liver. This view has been confirmed in studies in primary human hepatocytes and HepG2 cells, which showed that factors that increase ApoA-1/HDL secretion from hepatocytes also increase $\mathrm{HL}$ secretion (Figure 2). ${ }^{43}$ Chatterjee et al ${ }^{43}$ showed that overexpression of ApoA-I in HepG2 cells directly stimulated $\mathrm{HL}$ release from the cell surface. Conversely, a knockdown of ApoA-I expression with siRNA decreased $\mathrm{HL}$ release into the medium. Therefore, newly secreted HDL may be able to bind and displace cell surface $\mathrm{HL}$ (Figure 2). Alternatively, HL may associate with ApoA-l/HDL complexes intracellularly and be cosecreted with HDL.

$\mathrm{HDL}$ and $\mathrm{HL}$ secretion may also be affected by membrane reuptake and degradative pathways. Treatment of HepG2 cells and primary human hepatocytes with compounds that block ApoA-I retroendocytosis, also affect $\mathrm{HL}$ release. Linoleic acid phospholipids $(\mathrm{PL})$, such as dilinoleoylphosphatidylcholine, increase hepatic ApoA-I secretion by threefold and promote a twofold increase in $\mathrm{HL}$ release. ${ }^{43}$ Phospholipid treatment does not appear to affect $\mathrm{HL}$ transcription, because PLs have no effect on steady-state mRNA levels. ${ }^{43}$ Instead, PLs stimulate PPAR $\alpha$ expression ${ }^{44}$ and inhibit membrane nucleotide signaling events on the cell surface to block retroendocytic degradative pathways. ${ }^{45}$ The data suggest that PLs block membrane recycling pathways that promote the reuptake and degradation of cell surface proteins such as HL (Figure 2). Hepatic lipase degradation has been shown to be rate-limiting to HL secretion, and associated with the dimerization of the enzyme. ${ }^{46}$ Doolittle and colleagues ${ }^{46}$ showed that, when $\mathrm{HL}$ does not form an active dimeric complex, large amounts of monomeric $\mathrm{HL}$ accumulate in the cell and are rapidly degraded. These investigators later showed that both the maturation and homodimerization of $\mathrm{HL}$ and lipoprotein lipase may be governed by a chaperone protein in the endoplasmic reticulum, called lipase maturation factor $1 .{ }^{47}$
Hepatic lipase may be secreted from hepatocytes as an inactive enzyme. Stimulants of HL secretion can increase $\mathrm{HL}$ mass in the hepatocyte medium by two-fold, but have no effect on $\mathrm{HL}$ activity in the medium. ${ }^{43}$ This characteristic, which may be important to the regulation of $\mathrm{HL}$ phospholipase activity, is due to an inhibitory effect of the specific species of HDL with which $\mathrm{HL}$ is associated in the medium. As in the circulation, HL in hepatocyte medium is primarily associated with larger HDL complexes containing both ApoA-I and ApoA-II. Phospholipid treatment increases the secretion of both ApoA-I and ApoA- $-I^{43,45}$ and, as shown by Boucher et al, ${ }^{31}$ the association of $\mathrm{HL}$ with ApoA-II-enriched $\mathrm{HDL}$ directly inhibits HL hydrolytic activity.

\section{Conclusion}

An inverse relationship exists between blood TG and $\mathrm{HDL}$ levels. Low HDL levels are often associated with high TG in both men and women, and the combination of low HDL and high TG levels is related to an increased risk of developing $\mathrm{CHD} .{ }^{48} \mathrm{HDL}$ is a repository for regulatory apolipoproteins and alterations in HDL apolipoprotein composition can affect TG metabolism by influencing the function of both $\mathrm{HL}$ and LPL. Mutations in the LIPC gene may have a direct effect on $\mathrm{HL}$ function, or may indirectly affect lipolysis by causing reduced or dysfunctional HDL particles. ${ }^{7,8,10}$ Stimulants of hepatic HDL production may therefore act through cofactor pathways to stimulate lipolytic enzymes and enhance TG clearance. ${ }^{43}$ This may in part explain why drugs that increase HDL levels, such as the fibrates and niacin, also reduce plasma TG levels. ${ }^{49,50}$

\section{References}

1. Davignon J, Cohn JS: Triglycerides: a risk factor for coronary heart disease. Atherosclerosis 1996, 124 Suppl:S57-S64

2. Triglyceride Coronary Disease Genetics Consortium and Emerging Risk Factors Collaboration, Sarwar N, Sandhu MS, Ricketts SL, Butterworth AS, Di Angelantonio E, Boekholdt SM, Ouwehand W, Watkins H, Samani NJ, Saleheen D, Lawlor D, Reilly MP, Hingorani AD, Talmud PJ, Danesh J: Triglyceride-mediated pathways and coronary disease: collaborative analysis of 101 studies. Lancet 2010, 375: 1634-1639

3. Goldberg IJ: Lipoprotein lipase and lipolysis: central roles in lipoprotein metabolism and atherogenesis. J Lipid Res 1996, 37:693-707

4. Zambon A, Deeb SS, Pauletto P, Crepaldi G, Brunzell JD: Hepatic lipase: a marker for cardiovascular disease risk and response to therapy. Curr Opin Lipidol 2003, 14:179-189

5. Baroni MG, Berni A, Romeo S, Arca M, Tesorio T, Sorropago G, Di Mario U, Galton DJ: Genetic study of common variants at the Apo E, Apo Al, Apo CIII, Apo B, lipoprotein lipase (LPL), and hepatic lipase (LIPC) genes and coronary artery disease (CAD): variation in LIPC gene associates with clinical outcomes in patients with established CAD. BMC Med Genet 2003, 4:8-15

6. Connelly PW, Hegele RA: Hepatic lipase deficiency. Crit Rev Clin Lab Sci 1998, 35:547-572

7. McCaskie PA, Cadby G, Hung J, McQuillan BM, Chapman CM, Carter KW, Thompson PL, Palmer LJ, Beilby JP: The C-480T hepatic lipase polymorphism is associated with HDL-C but not with risk of coronary heart disease. Clin Genet 2006, 70:114-121

8. Hodoglugil U, Williamson DW, Mahley RW: Polymorphisms in the hepatic lipase gene affect plasma HDL-cholesterol levels in a Turkish population. J Lipid Res 2010, 51:422-430 
9. Teslovich TM, Musunuru K, Smith AV, Edmondson AC, Stylianou IM, Koseki M, et al: Biological, clinical and population relevance of 95 loci for blood lipids. Nature 2010, 466:707-713

10. Feitosa MF, Myers RH, Pankow JS, Province MA, Borecki IB: LIPC variants in the promoter and intron 1 modify HDL-C levels in a sexspecific fashion. Atherosclerosis 2009, 204:171-177

11. Jansen $H$, van Berkel TJ, Hülsmann WC: Binding of liver lipase to parenchymal and non-parenchymal rat liver cells. Biochem Biophys Res Commun 1978, 85:148-152

12. Kuusi T, Nikklä EA, Virtanen I, Kinnunen PK: Localization of the heparin-releasable lipase in situ in the rat liver. Biochem J 1979 181:245-246

13. Hahn PF: Abolishment of alimentary lipemia following injection of heparin. Science 1943, 98:19-20

14. Olivecrona T, Bengtsson-Olivecrona G, Ostergaard P, Liu G, Chevreuil O, Hultin M: New aspects on heparin and lipoprotein metabolism. Haemostasis 1993, 23 Suppl 1:150-160

15. Kuusi T, Ehnholm C, Viikari J, Härkönen R, Vartiainen E, Puska P, Taskinen MR: Postheparin plasma lipoprotein and hepatic lipase are determinants of hypo- and hyperalphalipoproteinemia. J Lipid Res 1989, 30:1117-1126

16. Patsch J: Influence of lipolysis on chylomicron clearance and HDL cholesterol levels. Eur Heart J 1998, 19 Suppl H:H2-H6

17. Santamarina-Fojo S, Haudenschild C, Amar M: The role of hepatic lipase in lipoprotein metabolism and atherosclerosis. Curr Opin Lipidol 1998, 9:211-219

18. Jansen $H$, Verhoeven AJ, Sijbrands EJ: Hepatic lipase: a pro- or anti-atherogenic protein? J Lipid Res 2002, 43:1352-1362

19. Ramsamy TA, Neville TA, Chauhan BM, Aggarwal D, Sparks DL: Apolipoprotein $A-I$ regulates lipid hydrolysis by hepatic lipase. J Biol Chem 2000, 275:33480-33486

20. Ramsamy TA, Boucher J, Brown RJ, Yao Z, Sparks DL: HDL regulates the displacement of hepatic lipase from cell surface proteoglycans and the hydrolysis of VLDL triacylglycerol. J Lipid Res 2003, 44:733-741

21. Rouhani N, Young E, Chatterjee C, Sparks DL: HDL composition regulates displacement of cell surface-bound hepatic lipase. Lipids 2008, 43:793-804

22. Young EK, Chatterjee C, Sparks DL: HDL-ApoE content regulates the displacement of hepatic lipase from cell surface proteoglycans. Am J Pathol 2009, 175:448-457

23. Sanan DA, Fan J, Bensadoun A, Taylor JM: Hepatic lipase is abundant on both hepatocyte and endothelial cell surfaces in the liver. $J$ Lipid Res 1997, 38:1002-1013

24. Hill JS, Yang D, Nikazy J, Curtiss LK, Sparrow JT, Wong H: Subdomain chimeras of hepatic lipase and lipoprotein lipase. Localization of heparin and cofactor binding. J Biol Chem 1998, 273:3097930984

25. Yu W, Hill JS: Mapping the heparin-binding domain of human hepatic lipase. Biochem Biophys Res Commun 2006, 343:659-665

26. Schoonderwoerd K, Verhoeven AJM, Jansen $\mathrm{H}$ : Rat liver contains a limited number of binding sites for hepatic lipase. Biochem J 1994 302:717-722

27. Brown RJ, Schultz JR, Ko KW, Hill JS, Ramsamy TA, White AL, Sparks $\mathrm{DL}$, Yao Z: The amino acid sequences of the carboxyl termini of human and mouse hepatic lipase influence cell surface association. J Lipid Res 2003, 44:1306-1314

28. Kolset SO, Salmivirta M: Cell surface heparan sulfate proteoglycans and lipoprotein metabolism. Cell Mol Life Sci 1999, 56:857-870

29. Tagashira $H$, Nakahigashi $S$, Kerakawati R, Motoyashiki T, Morita T: Involvement of $\mathrm{Ca}^{2+} /$ calmodulin-dependent protein kinase II in heparin-stimulated release of hepatic lipase activity from rat hepatocytes. Biol Pharm Bull 2005, 28:409-412

30. Mowri HO, Patsch Jr, Gotto AM Jr, Patsch W: Apolipoprotein A-II influences the substrate properties of human $\mathrm{HDL}_{2}$ and $\mathrm{HDL}_{3}$ for hepatic lipase. Arterioscler Thromb Vasc Biol 1996, 16:755-762
31. Boucher J, Ramsamy TA, Braschi S, Sahoo D, Neville TA, Sparks DL: Apolipoprotein A-II regulates HDL stability and affects hepatic lipase association and activity. J Lipid Res 2004, 45:849-858

32. Boucher JG, Nguyen T, Sparks DL: Lipoprotein electrostatic properties regulate hepatic lipase association and activity. Biochem Cell Biol 2007, 85:696-708

33. Blum CB: Dynamics of apolipoprotein $E$ metabolism in humans. J Lipid Res 1982, 23:1308-1316

34. Murdoch SJ, Breckenridge WC: Influence of lipoprotein lipase and hepatic lipase on the transformation of VLDL and HDL during lipolysis of VLDL. Atherosclerosis 1995, 118:193-212

35. Murdoch SJ, Breckenridge WC: Effect of lipid transfer proteins on lipoprotein lipase induced transformation of VLDL and HDL. Biochim Biophys Acta 1996, 1303:222-232

36. Mowri HO, Patsch W, Smith LC, Gotto AM JR, Patsch JR: Different reactivities of high density lipoprotein2 subfractions with hepatic lipase. J Lipid Res 1992, 33:1269-1279

37. Hime NJ, Drew KJ, Hahn C, Barter PJ, Rye KA: Apolipoprotein E enhances hepatic lipase-mediated hydrolysis of reconstituted highdensity lipoprotein phospholipid and triacylglycerol in an isoformdependent manner. Biochemistry 2004, 43:12306-12314

38. Deeb SS, Zambon A, Carr MC, Ayyobi AF, Brunzell JD: Hepatic lipase and dyslipidemia: interactions among genetic variants, obesity, gender, diet. J Lipid Res 2003, 44:1279-1286

39. Weisgraber KH, Mahley RW: Apoprotein (E-A-II) complex of human plasma lipoproteins. I. Characterization of this mixed disulfide and its identification in a high density lipoprotein subfraction. J Biol Chem 1978, 253:6281-6288

40. Jain MK, Berg OG: The kinetics of interfacial catalysis by phospholipase A2 and regulation of interfacial activation: hopping versus scooting. Biochim Biophys Acta 1989, 1002:127-156

41. Couillard C, Bergeron N, Prud'homme D, Bergeron J, Tremblay A, Bouchard C, Mauriège P, Després JP: Gender difference in postprandial lipemia: importance of visceral adipose tissue accumulation. Arterioscler Thromb Vasc Biol 1999, 19:2448-2455

42. Patsch Jr, Karlin JB, Scott LW, Smith LC, Gotto AM Jr: Inverse relationship between blood levels of high density lipoprotein subfraction 2 and magnitude of postprandial lipemia. Proc Natl Acad Sci USA 1983, 80:1449-1453

43. Chatterjee C, Young EK, Pussegoda KA, Twomey EE, Pandey NR, Sparks DL: Hepatic high-density lipoprotein secretion regulates the mobilization of cell-surface hepatic lipase. Biochemistry 2009, 48 : 5994-6001

44. Pandey NR, Renwick J, Misquith A, Sokoll K, Sparks DL: Linoleic acid-enriched phospholipids act through peroxisome proliferatoractivated receptors alpha to stimulate hepatic apolipoprotein A-I secretion. Biochemistry 2008, 47:1579-1587

45. Pandey NR, Renwick J, Rabaa S, Misquith A, Kouri L, Twomey E Sparks DL: An induction in hepatic HDL secretion associated with reduced ATPase expression. Am J Pathol 2009, 175:17771787

46. Ben-Zeev O, Doolittle MH: Maturation of hepatic lipase. Formation of functional enzyme in the endoplasmic reticulum is the rate-limiting step in its secretion. J Biol Chem 2004, 279:6171-6181

47. Doolittle $\mathrm{MH}$, Ehrhardt $\mathrm{N}$, Peterfy $\mathrm{M}$ : Lipase maturation factor 1 : structure and role in lipase folding and assembly. Curr Opin Lipidol 2010, 21:198-203

48. Castelli WP, Garrison RJ, Wilson PW, Abbott RD, Kalousdian S, Kannel WB: Incidence of coronary heart disease and lipoprotein cholesterol levels. The Framingham Study. JAMA 1986, 256:2835-2838

49. Staels B, Dallongeville J, Auwerx J, Schoonjans K, Leitersdorf E, Fruchart JC: Mechanism of action of fibrates on lipid and lipoprotein metabolism. Circulation 1998, 98:2088-2093

50. Kamanna VS, Kashyap ML: Nicotinic acid (niacin) receptor agonists: will they be useful therapeutic agents? Am J Cardiol 2007, 100:S53-S61 